\title{
Book Review: Gareth Millward, Vaccinating Britain: Mass Vaccination and the Public since the Second World War
}

Samantha Vanderslott

First Published July 3, 2019 Book Review

https://doi.org/10.1177/0963662519860722

Vaccinating Britain: Mass Vaccination and the Public since the Second World War Gareth Millward, Vaccinating Britain: Mass Vaccination and the Public since the Second World War. Manchester: University Press, 2019. 296 pp. f25 ISBN: 978-1-5261-2677-1

Historian Gareth Millward tells the story of how routine child immunisation became the status quo in Britain since 1945. While the preoccupation of health professionals has been with the parents who do not vaccinate, asking how we have reached the point where most parents do vaccinate is just as important.

Rather than taking a political party lens, Millward chose to concentrate on the public in a way that includes the citizen, state provision and public spheres. However, he is aware of political ideology, such as the emphasis of the Conservative government in the 1980s and 1990 s on vaccination as a preventive intervention to help to manage health costs through personal and parental responsibility. As an historian, Millward did not seek to analyse individual or social psychologies for vaccine decision-making but rather the construction of the public through government policy.

In the first part of the book, he examines the programmes for three vaccines. In chapter one, ('Diphtheria') he shows how health authorities explained a fall in immunisation rates in the 1950s through 'apathy'. Examining statistics and survey results, Millward finds these do not fit the definition of apathy as a declining fear of disease. Apathy acted as a framing device for the authorities; this was extended to a number of phenomena, including ignorance, indifference, disbelief and even wilful resistance. A publicity campaign was initiated to reverse the trend, and vaccination was made more convenient and attractive to parents: this included a response coordinated by local medical officers of health, the professionalisation of health visitors and the improvement of local services.

Chapter two ('Smallpox') portrays vaccination during outbreaks, including the policies of vaccination during epidemics, involving the control of borders and vaccination of hospital staff. The smallpox outbreaks of 1949 and 1950 - both examples of importation demonstrated how vaccination was a tool against foreign contagion and associated threats to travel and trade, as well as raising issues of immigration.

The third chapter ('Poliomyelitis') covers the launch of the British inactivated polio vaccine in 1956 and the switch to the oral polio vaccine in 1962. British health authorities, cautious after a high-profile US laboratory accident, created their version of the vaccine that would be continually affected by supply problems. 
Part II of the book covers vaccination crises arising from public scepticism and scientific controversy and juxtaposes the pertussis ('whooping cough') crisis of the 1970s with the measles, mumps and rubella (MMR) crisis of the 1990s. In chapter four ('Pertussis'), instead of fixating on why exactly parents were not vaccinating, Millward extends his view to the other issues the debate was tied up with. There were concerns and anxieties related to the relative risk of vaccine damage and of the infectious disease itself. Debates were also happening in the 1960s/1970s about poverty caused by disability and the need for an adequate safety net for those who became ill or were disabled; here, Millward's expertise in disability policy becomes clearly evident.

The author really excels in the last chapter ('MMR'), revisiting this crisis in historical detail and showing that the portrayal of the public as 'anti-vaccine' is inaccurate. The primary public debate concerned whether separate MMR vaccines, rather than a single combined vaccine, should be given to children. Several aspects are often left out in accounts of how the 1998 paper by Andrew Wakefield and colleagues in The Lancet was retracted. Millward recalls that the journal printed a repudiation alongside the original paper and that it was at a press conference that Wakefield claimed MMR was dangerous and separate MMR jabs should be sought. The wider historical context tends to be lost, including how scientific authority had been placed in doubt by the thalidomide birth defect crisis of the 1960s and 'mad cow disease' (bovine spongiform encephalopathy (BSE)) crisis of the early 1990s.

It is a little surprising that Millward does not reference Ben Goldacre's argument in Bad Science (2008) that the mainstream media inflamed the crisis. Millward does engage with the media's role but could have given them more attention. Although the book focuses on the United Kingdom, a reference to the influence of ideas from US autism communities or to debates connected to MMR that have continued elsewhere in the world would also have been useful. The interaction between the United Kingdom and other countries (the United States) was central to the chapter on polio, but it could have been extended to the other case studies as well. Overall, however, for anyone interested in vaccination issues today, Vaccinating Britain is a must-read, and it elegantly locates public discourse, policies and events in social context.

\section{Author biography}

Samantha Vanderslott is a postdoctoral researcher at the University of Oxford at the Oxford Vaccine Group and Oxford Martin School. Her PhD is in Science and Technology Studies from University College London. Her current research is about public attitudes, media portrayal and government policies towards vaccination. On this topic, her most recent publication was 'Exploring the meaning of pro-vaccine activism across two countries', Social Science and Medicine (February 2019). 